\title{
Where do these bugs come from? Phenotypic structure of Triatoma infestans populations after control interventions in the Argentine Chaco
}

\author{
María Sol Gaspe, Yael Mariana Provecho, Romina Valeria Piccinali, Ricardo Esteban Gürtler/+ \\ Laboratory of Eco-Epidemiology, Department of Ecology, Genetics and Evolution, Instituto de Ecología, Genética y Evolución, \\ Consejo Nacional de Investigaciones Científicas y Técnicas, Universidad de Buenos Aires, Buenos Aires, Argentina
}

\begin{abstract}
House re-invasion by native triatomines after insecticide-based control campaigns represents a major threat for Chagas disease vector control. We conducted a longitudinal intervention study in a rural section (Area III, 407 houses) of Pampa del Indio, northeastern Argentina, and used wing geometric morphometry to compare pre-spray and post-spray (re-infestant bugs) Triatoma infestans populations. The community-wide spraying with pyrethroids reduced the prevalence of house infestation by $\mathrm{T}$. infestans from $31.9 \%$ to $<1 \%$ during a four-year follow-up, unlike our previous studies in the neighbouring Area I. Two groups of bug collection sites differing in wing shape variables before interventions (including 221 adults from 11 domiciles) were used as a reference for assigning 44 post-spray adults. Wing shape variables from post-spray, high-density bug colonies and pre-spray groups were significantly different, suggesting that re-infestant insects had an external origin. Insects from one house differed strongly in wing shape variables from all other specimens. A further comparison between insects from both areas supported the existence of independent re-infestation processes within the same district. These results point to local heterogeneities in house re-infestation dynamics and emphasise the need to expand the geographic coverage of vector surveillance and control operations to the affected region.
\end{abstract}

Key words: Triatoma infestans - re-infestation - geometric morphometry - Gran Chaco - vector control

Chagas disease, one of the main neglected tropical diseases in Latin America, affects seven-10 million people (WHO 2013). In the absence of an effective vaccine, the main strategy to reduce or interrupt vectorborne transmission of Trypanosoma cruzi is associated with the elimination or reduction of domestic triatomine populations, mainly through the application of insecticide. These interventions suppressed Triatoma infestans, the main vector species in the Southern Cone countries, from a large area of its original geographic range (Schofield et al. 2006). However, in the Gran Chaco ecoregion, which includes sections of Argentina, Paraguay and Bolivia, the degrees of success were much lower and high levels of house infestation and parasite transmission still occur (Gürtler et al. 2007, Gorla et al. 2009, Gürtler 2009, Samuels et al. 2013).

The interruption of the household transmission of $T$. cruzi in many regions is threatened by house re-invasion by native vectors (Abad-Franch et al. 2013). Post-spray house infestation in the Gran Chaco region has been related to a reduced effectiveness of pyrethroid insecticides in peridomestic sites (Gürtler et al. 2004, Porcasi

doi: 10.1590/0074-02760140376

Financial support: University of Buenos Aires, ANPCyT (PICT, PICTO-GLAXO), CONICET (PIP) (to REG)

+ Corresponding author: gurtler@ege.fcen.uba.ar

Received 10 October 2014

Accepted 18 March 2015 et al. 2006, Cecere et al. 2013), pyrethroid resistance (Germano et al. 2010, Lardeux et al. 2010, Gurevitz et al. 2012) and active or passive bug dispersal from infested communities (Vázquez-Prokopec et al. 2004, Cecere et al. 2006, Abrahan et al. 2011) or from sylvatic foci (Noireau et al. 2005, Ceballos et al. 2011, Brenière et al. 2013). Understanding the re-infestation process includes searching for the putative origins of re-infestant insects (Schofield et al. 2006, Dujardin et al. 2007) and is a key aspect of Chagas disease vector control.

Several genetic markers have been used to identify the putative origins of re-infestant triatomines through comparisons between specimens captured before and after control interventions and in sylvatic habitats (Dujardin et al. 1996, Dumonteil et al. 2007, Fitzpatrick et al. 2008, Marcet et al. 2008, Brenière et al. 2013). More recently, geometric morphometry has emerged as a low-cost methodology showing promising results in the identification of re-infestation sources (Dujardin et al. 2007, Feliciangeli et al. 2007, Gaspe et al. 2013, Hernández et al. 2013). The first step toward this goal is to assess the level of spatial structuring of vector populations before implementing control interventions. The outcomes of these studies may be used to design control strategies adapted to specific vector population features and local contexts (Kaba et al. 2012).

As part of a longitudinal study on the ecoepidemiology and control of Chagas disease in northern Argentina, we investigated the processes underlying house infestation patterns before and after control interventions in a rural section (Area I) of Pampa del Indio, Chaco (Gurevitz et al. 2011, 2012). A community-wide (blanket) house spraying with pyrethroid insecticides aiming at full-coverage reduced the prevalence and abundance 
of house infestation by $T$. infestans much less than expected, primarily due to the occurrence of moderate pyrethroid resistance leading to vector control failures (Gurevitz et al. 2012). Wing geometric morphometry analyses revealed that pre-spray bug populations were spatially structured and post-spray insects most likely originated from residual foci that survived insecticide sprays (Gaspe et al. 2012, 2013). To further test the generality of these results, we expanded the scope and geographic scale of the research and control operations to a neighbouring rural section (Area III) of Pampa del Indio, which also had high pre-intervention infestation, but contrasting environmental, socio-demographic and cultural characteristics (Gaspe et al. 2015).

The stronger impact of the community-wide insecticide spraying in Area III and associated re-infestation patterns prompted us to assess the similarity between pre-spray and post-spray (reinfestant) populations and to compare insects from Areas I and III using wing geometric morphometry. We initially hypothesised that house re-infestation in Area III would derive from residual bug populations, as in Area I. Our study sheds light on sizable heterogeneities between neighbouring rural areas within the same district and further supports the use of wing geometric morphometry to investigate house re-infestation.

\section{MATERIALS AND METHODS}

Study area - Field work was conducted in a rural sec-

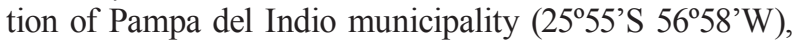
which for vector control purposes was divided into four areas each including 300-400 dwellings in which similar intervention protocols were performed. The current study was conducted in a $95 \mathrm{~km}^{2}$ rural section (Area III) including 407 inhabited houses as of October 2008 and was mainly occupied by Qom communities and a Creole minority (Gaspe et al. 2015). Most houses had mud walls with plenty of refuges for triatomines, were small-sized $\left(<30 \mathrm{~m}^{2}\right)$ and recently built and had few or no peridomestic structures and little access to electricity. The last insecticide spraying campaign conducted in the municipality occurred in 19971998 and selective sprays of a few houses in Area III were conducted in 2000 and 2006 by local health workers.

A house compound was defined as the set of human sleeping quarters (i.e., domestic sites) and structures included within the peridomestic area (e.g., kitchens, storerooms, corrals, chicken coops) as illustrated elsewhere (Gurevitz et al. 2011). The location of each house was georeferenced (Garmin Legend) and the geographic distance between houses was assessed using ArcGis 9.2.

Study design - A longitudinal study was conducted in Area III to monitor house infestation over a four-year period before and after community-wide spraying with insecticides. All structures within each house compound were searched for triatomine bugs by timed manual collections using a dislodjant aerosol $(0.2 \%$ tetramethrin) (Espacial, Argentina) conducted by two skilled bug collectors from the national or provincial vector control programs (Gaspe et al. 2015). T. infestans was found by timed-manual searches in $28 \%$ of the 386 inhabited houses inspected at baseline (October 2008). House in- festation rose to $31.9 \%$ when all collection methods were considered. All sites within each house compound were sprayed with pyrethroid insecticides immediately after the baseline survey (November 2008) as described elsewhere (Gurevitz et al. 2012); the house spray coverage achieved was $94 \%$. Post-intervention annual surveys aiming at full coverage were conducted at 10 months post-spray (MPS) (August 2009), 18 MPS (April 2010), 38 MPS (December 2011) and 49 MPS (November 2012). Only a sample of the inhabited households was inspected at 38 MPS and included households deemed to be at a higher infestation risk. Selective sprays of the reinfested houses were performed immediately after completing each annual house survey in a similar fashion. Additional methods to assess bug infestation were performed during the follow-up to improve the detectability of house infestation: (i) collection of bugs that were spotted during insecticide spraying operations and (ii) householders' collection of any triatomine they sighted.

Insects - To assess the spatial structuring of baseline insect populations, we selected collection sites with at least 10 adult $T$. infestans of the same sex for wing geometric morphometry analysis. A random sample of 15 insects of the same sex per site was chosen to achieve balanced sample sizes in the few cases in which the total adult catch exceeded that number. In total, 132 males from 11 domiciles and 89 females from eight domiciles were analysed (Fig. 1B).

To determine the putative origin of re-infestant insects, all adult bugs collected in each post-spray survey were analysed except the only adult bug collected at 38 MPS (Table), which had its wings in poor condition and therefore was excluded from the analysis. Males and females collected in one domicile (PC152) at 10 MPS were included as re-infestant insects to preserve the temporal specificity of pre-spray bug populations despite the fact that this house had not been inspected or sprayed at baseline. House PC152 was located at more than $1.5 \mathrm{~km}$ from the nearest inhabited house and was surrounded by patches of dense forest.

Pre and post-spray triatomines were compared with those collected before insecticide applications in Area I, which included 93 males and 89 females from the two geographic groups identified (Gaspe et al. 2012) (Fig. 1A).

Metric data - Right wings were mounted between slides and cover slips and photographed using a digital camera (Sony MVCCD300, USA) and a stereo-microscope (Zeiss SV11, Germany) as described in SchachterBroide et al. (2004). We used 10 type-I landmarks (vein intersections) identified for $T$. infestans wings as described elsewhere (Gaspe et al. 2012).

The isometric estimator known as centroid size (cs), defined as the square root of the sum of the squared distances between the centre of the configuration of landmarks and each individual landmark (Bookstein 1990), was used to compare sexes, collection sites, surveys and study areas. Size comparisons were performed for males and females separately using Mann-Whitney $U$ and Kruskal-Wallis tests implemented in Stata 12.0 software (Stata Corp LP, USA). 


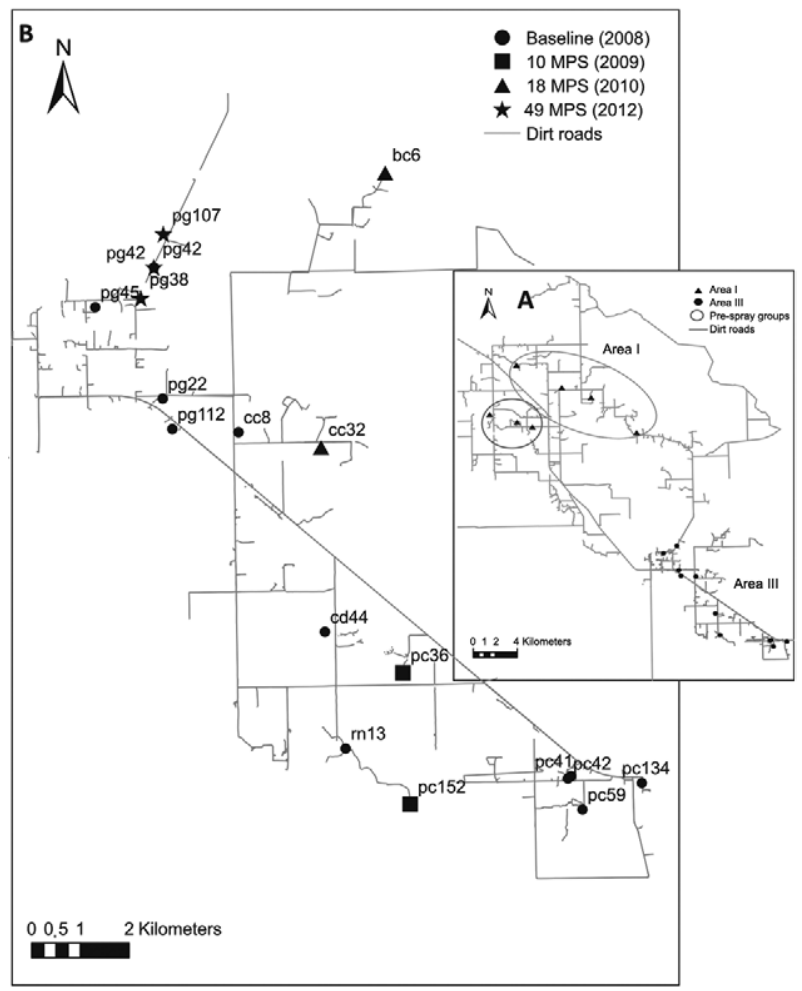

Fig. 1A: map showing houses infested by Triatoma infestans before insecticide spraying which were included in wing geometric morphometry analyses in Area III (circles) and the groups of houses identified in Area I (triangles) (Gaspe et al. 2012), Pampa del Indio, Chaco, 20072008; B: map of Area III showing houses infested by T. infestans included in the morphometric analyses by survey, Pampa del Indio, 20082012. Circles show houses before insecticide spraying (October 2008), squares correspond to the first post-spray survey [10 months post-spray (MPS), 2009], triangles correspond to the second post-spray survey (18 MPS, 2010) and stars to the fourth post-spray survey (49 MPS, 2012), the numbers and letters refer to the house ID. The letters correspond to the name of the community (cc: Cuarta Legua 14; cd: Cuarta Legua 17; pc: Pampa Chica; pg: Pampa Grande; rn: El Rincón).

Shape variables [partial warps (PW)] were obtained using the Generalized Procrustes Analysis superimposition algorithm (Rohlf 1996). To avoid having small sample sizes relative to the number of variables, we used a restricted representation of shape (i.e., a set of principal components known as relative warps) derived from shape variables. In all cases, $>90 \%$ of total shape variation was explained. Residual allometry was estimated by multivariate regression of PW on size (Good 2000). Mahalanobis distances were derived from the selected set of relative warps and then used to construct an unweighted pair-group method with arithmetic average (UPGMA) dendrogram. The statistical significance of these distances was computed by nonparametric permutation tests (1,000 runs) adjusted by the Bonferroni procedure.

To analyse the occurrence of spatial structuring of baseline bug populations, Mahalanobis distances were used to perform a simple reclassification test for each indi- vidual bug. The percentage of males and females that were correctly assigned to the corresponding geographic group was assessed. The isolation-by-distance (IBD) model for each sex was tested by regressing Mahalanobis distance on geographic distance between bug collection sites with a Mantel test. Significance levels were determined by 1,000 permutations using IBD (Bohonak 2002).

To assess the putative origin of re-infestant insects, two different analyses were performed due to the small number of adult bugs collected in some sites. Post-spray insects were entered one by one to the discriminant analysis of pre-spray samples and assigned to the closest reference group according to Mahalanobis distances as described elsewhere (Dujardin et al. 2010, Gaspe et al. 2013). For post-spray bugs collected in houses not included in the pre-spray sample, the nearest infested house at baseline was taken as the reference. Additionally, the adults from high-density post-spray bug colonies (i.e., $>10$ adults collected) were analysed together with the pre-spray groups. The Mahalanobis distances among post-spray collection sites and the pre-spray groups were compared by nonparametric permutation tests and reclassification tests were performed.

Field data and interviews with householders suggested that the infestations of houses PG38 and PG107 in the 49 MPS survey could have originated from the highdensity bug colony found in the neighbouring house PG42. To test this hypothesis, we performed additional analyses considering the highly infested household detected in the 49 MPS survey and before communitywide spraying (PG42) as reference groups.

To verify the quality of the re-classification analysis and to assess the confidence levels of post-spray assignments, a cross-checked classification of males and females in pre and post-spray reference groups was performed. Each individual was removed, treated as external data and then re-assigned to one of the groups. The percentage of correctly assigned specimens was computed for each reference group.

Mitochondrial DNA - Due to the strong morphometric differentiation found in insects from $\mathrm{BC} 06$, two individuals were sequenced for a fragment of the mitochondrial gene cytochrome oxidase I ( $m t C O I)$ as described in Piccinali et al. (2009). The sequences were compared with a database of haplotypes from $650 \mathrm{~T}$. infestans individuals from Argentina, Bolivia, Uruguay and Paraguay, including individuals from the neighbouring Area I.

Software - TPSDig2 v.2.09 was used for landmark digitalisation, MOG for Procrustes superimposition, generation of PW, assignment of "unknown specimens" and validated re-classification tests, VAR for nonparametric comparisons of $c s, \mathrm{COV}$ for examination of residual allometry within shape variables and common allometry model tests and PAD for discriminant analyses, non parametric permutation tests and re-classification tests. TpsDig2 was developed by FJ Rohlf and is available from life.bio.sunysb/morpho. The modules MOG, VAR, COV, PAD developed by JP Dujardin, are included in the CLIC package available from mome-clic.com. 
TABLE

Distribution of Triatoma infestans males and females included in morphometric analyses and the results of the putative origin of post-spray bugs according to bug collection ecotope and survey in Area III, Pampa del Indio, Chaco, Argentina, 2008-2012

\begin{tabular}{|c|c|c|c|c|c|c|c|c|c|}
\hline Survey & $\begin{array}{c}\text { Date of } \\
\text { bug collection }\end{array}$ & House & Ecotope & Males & Females & Total & $\begin{array}{c}\text { Bugs } \\
\text { assigned }^{a} \\
(\%)\end{array}$ & $\begin{array}{l}\text { Comparison with } \\
\text { pre-spray groups } \\
\text { (p) }\end{array}$ & $\begin{array}{l}\text { Distance to the } \\
\text { nearest house } \\
(\mathrm{km})^{c}\end{array}$ \\
\hline Baseline & October 2008 & 11 houses & Domicile & 132 & 89 & 221 & - & - & - \\
\hline \multirow[t]{9}{*}{ Post-spray } & 10 MPS (2009) & PC36 & Domicile & 1 & 1 & 2 & 100 & - & 1.8 \\
\hline & & PC152 & Domicile & 4 & 5 & 9 & 22 & $<0.05$ & 2.7 \\
\hline & 18 MPS (2010) & $\mathrm{BC} 06$ & Chicken coop & 5 & 6 & 11 & 55 & $<0.05$ & 6.5 \\
\hline & & $\mathrm{CC} 32$ & Domicile & 1 & 1 & 2 & 50 & - & 1.7 \\
\hline & 38 MPS (2011) & PG156 & Domicile & $0^{d}$ & 0 & $0^{d}$ & - & - & - \\
\hline & 49 MPS (2012) & PG38 & $\begin{array}{l}\text { Domicile and } \\
\text { chicken coop }\end{array}$ & 1 & 1 & 2 & 50 & - & 0.7 \\
\hline & & PG42 & Domicile & 3 & 11 & 14 & 40 & $<0.05$ & 1.4 \\
\hline & & PG107 & Domicile & 4 & 0 & 4 & 75 & - & 0.8 \\
\hline & Total & - & - & 19 & 25 & 44 & - & - & - \\
\hline Total & & - & - & 151 & 114 & 265 & - & - & - \\
\hline
\end{tabular}

$a$ : analysed using the one-by-one procedure that assigned each individual to the previously identified pre-spray groups. The results correspond to the percentage of insects assigned to the nearest house; $b$ : the results correspond to the comparison of Mahalanobis distances between the post-spray house and pre-spray groups. The significance level was determined by nonparametric permutation tests. Only high-density post-spray bug populations were included; $c$ : considering pre-spray groups; $d$ : the only adult bug collected at the 38 months post-spray (MPS) survey had its wings in poor condition and therefore was excluded from the analyses.

\section{RESULTS}

House re-infestation by T. infestans - Baseline house infestation by $T$. infestans $(31.9 \%)$ dropped sharply and remained below $1 \%$ during the four-year follow-up after community-wide insecticide spraying of Area III, unlike in neighbouring Area I (Fig. 2). No additional house was found infested by $T$. infestans as determined by householders' bug collections during the entire followup, whereas several adult specimens of nondomiciliated species (mainly Triatoma sordida) were collected, supporting the very low prevalence of T. infestans.

House infestation by $T$. infestans was concentrated in domiciles both before and after community-wide spraying. Seven of the 10 houses found re-infested after initial insecticide spraying had not been found infested at baseline and none of the infested houses sprayed selectively during the follow-up was found infested again. Only two houses had also been infested at baseline: one of which had a large bug colony (included in the baseline sample) and the other one only had one adult bug (not included in the baseline sample).

Spatial structuring of pre-spray bug populations Female wing $c s$ [mean $=754.8 \mathrm{~mm}$; standard deviation $(\mathrm{SD})=29.6 \mathrm{~mm}$ ] was significantly larger than male $c s$ (mean $=721.9 \mathrm{~mm}$; SD = $25.8 \mathrm{~mm})$ (Mann-Whitney $U$ test, $\mathrm{p}<0.001)$. Significant differences in $c s$ were found among bugs from different collection sites both in males [Kruskal-Wallis $U$ test, degree of freedom (d.f.) $=10 ; \mathrm{p}<$ $0.01]$ and females (d.f. $=7 ; \mathrm{p}<0.01$ ). No significant dif- ferences were found in the wing $c s$ of males and females from Areas III and I collected before insecticide spraying (Mann-Whitney $U$ test, $\mathrm{p}>0.05$ ).

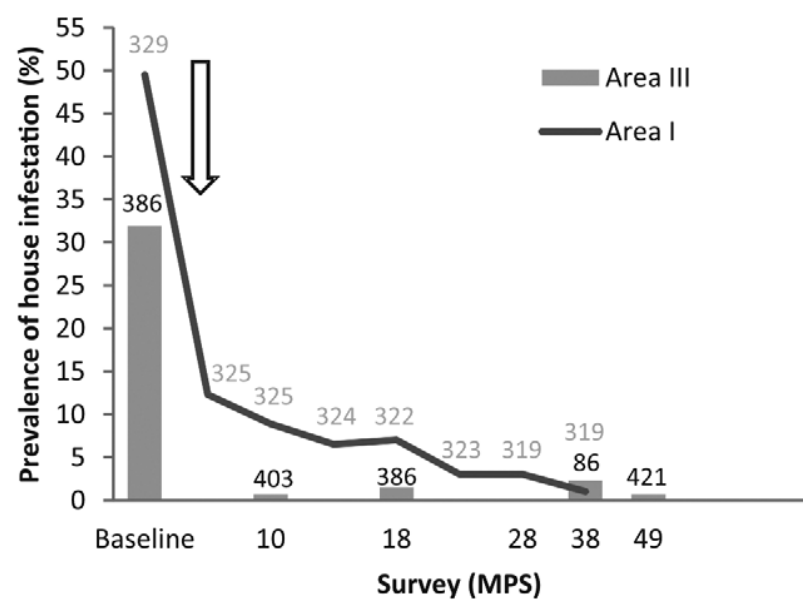

Fig. 2: prevalence of house infestation by Triatoma infestans during the follow-up in Area III (bars) and Area I (dots), Pampa del Indio, Chaco, Argentina. The white arrow shows the timing of communitywide insecticide spraying campaigns. After each survey re-infested houses were re-sprayed with pyrethroids. Numbers above bars indicate the number of houses inspected for infestation in Area III (black) and Area I (grey). MPS: months post-spray. 


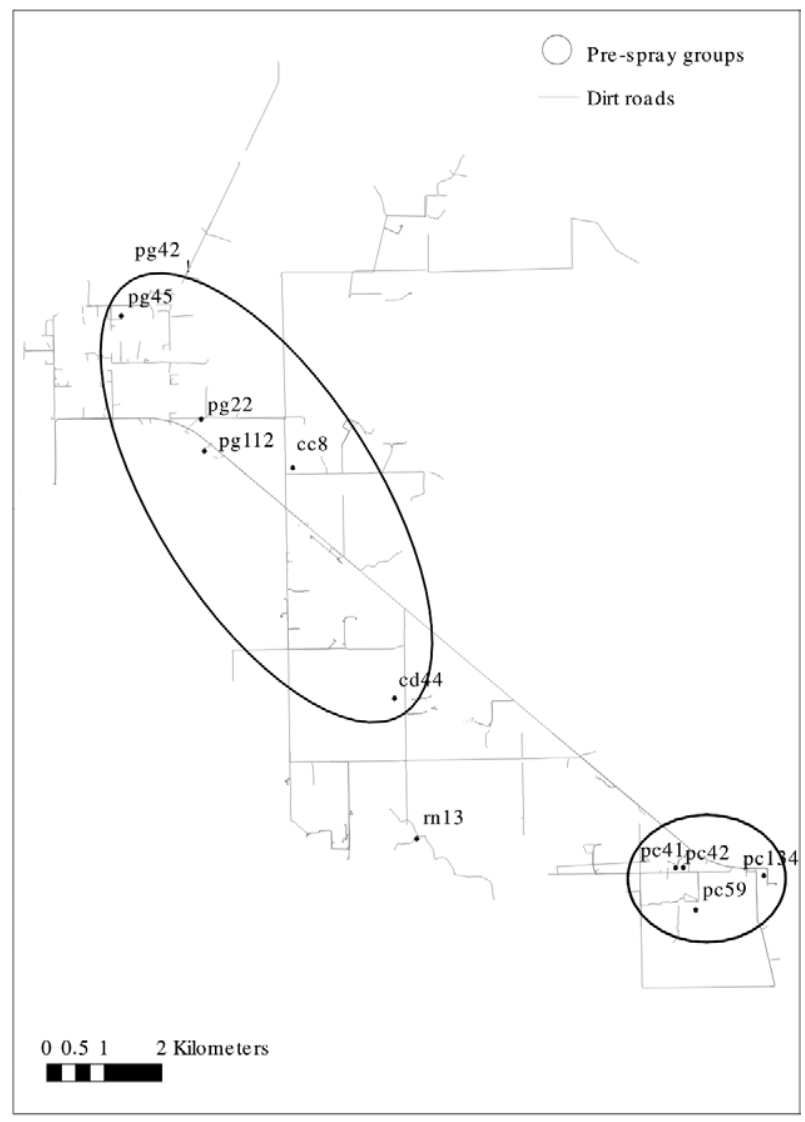

Fig. 3: map of Area III showing the pre-spray groups of Triatoma infestans identified by wing geometric morphometry, Pampa del Indio, Chaco, Argentina, 2008. The numbers and letters in the map refer to the house ID. The letters correspond to the name of the community (cc: Cuarta Legua 14; cd: Cuarta Legua 17; pc: Pampa Chica; pg: Pampa Grande; rn: El Rincón).

Given the absence of significant differences in wing shape variables between males and females collected at the same site, the analyses were performed considering both sexes pooled by site. The analyses showed the existence of two groups that included bug collection sites with no significant differences in Mahalanobis distances, whereas collection sites from different groups were significantly different. No residual allometric effect was found, suggesting that the differences observed were not caused by wing size. The two groups corresponded to geographic groups including sites located at a mean distance of 1 and $3 \mathrm{~km}$ from one another, respectively (Fig. 3), whereas sites from different groups were located at a mean distance of $10 \mathrm{~km}$ (range, 6-13 km). Mahalanobis and geographic distances were significantly correlated (Mantel test, $\mathrm{r}=0.36$, $\mathrm{p}<0.01)$. Both simple and cross-checked re-classification scores were higher than $72 \%$ for both groups and supported their validity as reference groups.

Significant differences in wing shape variables among these two groups and those identified in Area I before community-wide insecticide application were found. The UPGMA dendrogram showed that groups within the same
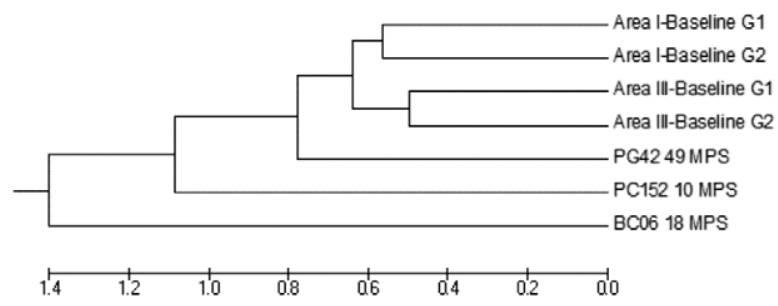

Fig. 4: unweighted pair-grouped method with arithmetic average (UPGMA) dendrogram derived from Mahalanobis distances between male and female Triatoma infestans collected before communitywide insecticide spraying in two neighbouring study Areas (III and I) and high-density post-spray collection sites of Area III, Pampa del Indio, Chaco, Argentina. G1 and G2 correspond to the two different geographic groups recovered for each area. The remainder groups correspond to high-density bug colonies in each post-spray survey [10 months post-spray (MPS), 18 MPS and 49 MPS].

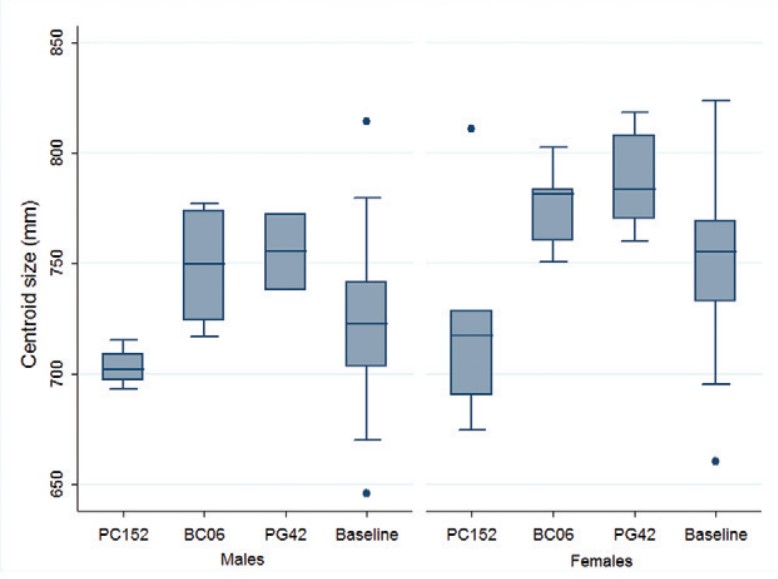

Fig. 5: wing centroid size of male and female Triatoma infestans collected before community-wide insecticide spraying (males, $\mathrm{n}=104$; females, $n=74$ ) and in each post-praying survey (males, $n=4,5,3$; females, $\mathrm{n}=5,6,11$, respectively), Pampa del Indio, Chaco, Argentina, 2008-2012. Letters and numbers correspond to the house ID. PC152 was infested at 10 months post-spray (MPS) (2009), BC06 at 18 MPS (2010) and PG42 at 49 MPS (2012).

area were more similar than those from different areas (Fig. 4). No residual allometry was found, indicating that these differences were not attributable to wing size effects.

Reinfestant insects - The wing cs of post-spray females was significantly larger than that of post-spray males (Mann-Whitney $U$ test, $\mathrm{p}<0.01$ ). The wing $c s$ of males and females significantly differed according to bug collection site and survey date (including pre and postspray surveys) (Kruskal-Wallis $U$ test, $\mathrm{p}<0.01$ in both sexes). Insects collected in house PC152 (domicile) at 10 MPS had significantly smaller $c s$ than those collected in other houses with a high-density infestation detected after insecticide spraying (including a domicile and a chicken coop). The pre-spray frequency distribution of $c s$ values was overdispersed, probably due to the inclusion of insects collected in several dwellings (Fig. 5). 


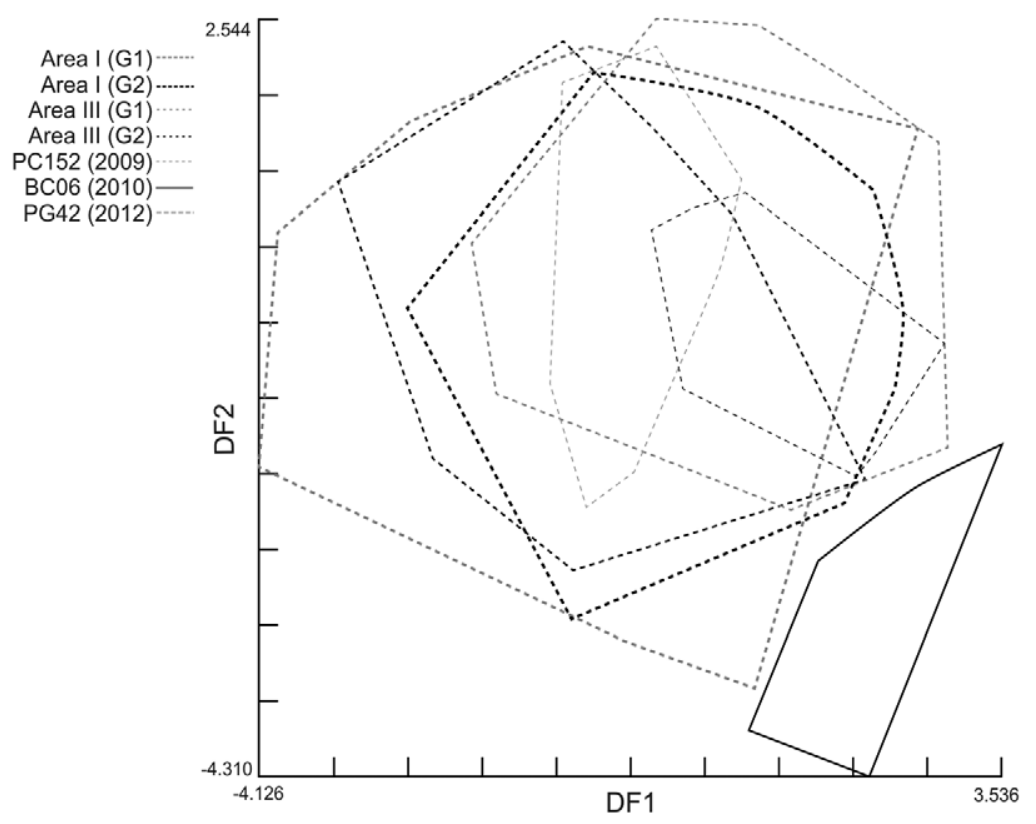

Fig. 6: factorial map of the discriminant analysis (1st vs. 2nd discriminant factor) of wing shape variables of Triatoma infestans males and females collected before community-wide insecticide spraying in two neighbouring study areas and in high-density collection sites after spraying, Pampa del Indio, Chaco, Argentina. CV1 and CV2 explained nearly 50\% of the total variance. G1 and G2 correspond to pre-spray bug collection sites with no significant differences in shape variables within each area. The remainder groups correspond to highly-abundant bug colonies in each post-spray survey [10 months post-spray (MPS), 18 MPS, 49 MPS].

For sites with high-density post-spray infestations, significant Mahalanobis distances were found with respect to pre-spray groups from Area III (t) and Area I $(\mathrm{p}<0.01)$ (Fig. 4). Post-spray adult bugs from house BC06 strongly differed from all other groups in Area III (complete line vs. broken-line polygons in Fig. 6 and Supplementary data) and in Area I (Fig. 4). The reclassification percentages of insects in each group were $64-66 \%$, whereas for house $\mathrm{BC} 06$ it was $90 \%$. To test for any procedural bias, insects from $\mathrm{BC} 06$ were digitised again, re-analysed and the initial results confirmed. These re-infestant specimens were confirmed to be $T$. infestans through $m t C O I$ sequencing and had the same haplotype as most insects from Area I (RV Piccinali et al., unpublished observations). This haplotype, called "c" previously, was the most frequent in the Argentine Chaco (Piccinali et al. 2009, 2010).

All the adult bugs collected at 10 MPS in the only low-density infested site were assigned to the nearest reference group. The percentage of assignment dropped to $50-75 \%$ for insects collected at 18 and 49 MPS (Table). Half of the insects collected in houses PG38 and PG107 at 49 MPS were assigned to the high-density bug colony detected in house PG42 during the same survey.

\section{DISCUSSION}

This study does not support our a priori hypothesis that the detected re-infestations during the four-year follow-up of Area III were primarily due to residual foci that survived community-wide insecticide spraying, unlike in Area I (Gurevitz et al. 2012, Gaspe et al.
2013). Sites with high-density bug colonies after initial insecticide spraying displayed significant differences in wing shape variables compared with pre-spray groups, suggesting that the former insects most likely originated from external sources (i.e., houses from outside Area III or putative sylvatic foci). Moreover, pre and post-spray insects from Area III were significantly different from those collected in Area I, supporting the existence of independent re-infestation processes within the same district. In addition, insects from house BC06 showed large, unexpected differences in wing shape variables with respect to all other insects analysed.

Wing geometric morphometry of pre-spray bug populations identified two groups of collection sites with significant differences in shape variables that corresponded to geographic locations. Bug collection sites grouped together were located at a mean distance of 1-3 km whereas sites from the two groups were $10 \mathrm{~km}$ apart, which largely exceeds the current estimates of the flight range of T. infestans (Schweigmann et al. 1988, Schofield et al. 1992). The geographic distribution of $T$. infestans populations fitted to the IBD model, as in Area I (Gaspe et al. 2012). This level of spatial structuring in Area III was very similar to the patterns recorded in Area I where no official blanket insecticide spraying had occurred during the previous decade. The sporadic selective sprays reported in some communities of Area III, combined with the high levels of house instability and household mobility detected (Gaspe et al. 2015), may have caused bottleneck events that led to the observed differentiation of pre-intervention $T$. infestans populations. 
The results of wing shape analyses of insects collected after blanket insecticide spraying suggest that reinfestations were very unlikely to derive from residual bug populations that survived the insecticide spraying campaign. This proposition is consistent with the very low prevalence of house infestation recorded during the four-year follow-up and the fact that most houses infested after initial spraying had not been infested at baseline. Of note, the municipality of Pampa del Indio was surrounded by rural districts with variable rates of house infestation, which were under sporadic vector surveillance and control operations; passive bug transport from these potential sources may have provided the post-spray insects in Area III. Although much less likely, internal re-infestation sources such as undetected foci within Area III or sylvatic foci of T. infestans s so far not detected in Pampa del Indio [Alvarado-Otegui et al. (2012), YM Provecho, unpublished observations] cannot be completely excluded. In contrast, in Area I, both the space-time analysis of site-specific infestations and wing geometric morphometry indicated that postspray triatomines were mainly survivors or the offspring of pre-spray bug populations (Gurevitz et al. 2012, 2013, Gaspe et al. 2013). Likewise, Rhodnius prolixus and T. infestans collected after insecticide applications elsewhere were primarily survivors from pre-spray bug populations and included some insects invading from nearby habitats (Feliciangeli et al. 2007, Hernández et al. 2013). Further studies using additional markers are needed to identify the most likely mechanism underlying house reinfestation after blanket interventions in Area III.

Pre-spray insects from Area III were significantly different from pre-spray bugs from Area I. Moreover, post-spray triatomines from sites with high-density colonies in Area III also differed from pre-spray insects from Area I. These results suggest a low rate of exchange of insects between these neighbouring rural areas and are of great relevance for improved vector surveillance. Bug populations involved in vector control failures in Area I were unlikely to represent an immediate risk for dwellings in Area III and therefore vector control actions can be (and were) decided in a relatively independent way.

Unexpected, large differences in wing shape variables occurred in post-spray triatomines from house $\mathrm{BC} 06$ relative to all other bugs despite the fact they had the most common $m t C O I$ haplotype found in Area I and in the Chaco region (RV Piccinali et al., unpublished observations). This house was located more than $5 \mathrm{~km}$ from the nearest infested house and belonged to a community that mainly included dispersed houses. These results suggest that the insects from BC06 had a different origin or that this specific bug population was reducing the exchange of individuals with the surrounding bug populations. Additional markers are needed to investigate the strong differences detected between bugs from house $\mathrm{BC} 06$ and the rest.

The wing $c s$ of pre-spray insects showed significant differences among collection sites for both sexes despite the fact that they had been collected at the same type of ecotope and month (Schachter-Broide et al. 2004, 2009, Hernández et al. 2011, Gaspe et al. 2012). Moreover, the wing $c s$ of males and females collected in one domicile at
10 MPS (which had not been treated with insecticides at the time of community-wide interventions) were significantly smaller than the $c s$ of insects collected in every infested house before and after interventions. These wing size variations support the existence of a large degree of differentiation among the study bug populations and may be associated with a limited exchange of insects among some of them. Consideration of additional factors known to affect wing size (i.e., bug density and host-feeding source, among others) may help explain the observed differences.

Our study has both limitations and strengths. The criteria used to select pre-spray samples restricted the analyses to domestic insects. The absence of abundant bug colonies across the study area and some methodological restrictions hindered the assignment of post-spray insects to the two reference groups identified. The few insects collected after community-wide interventions during the four-year follow-up limited the analyses of post-spray populations using conventional procedures. This issue was addressed through one-by-one assignments and by using additional field data to contrast the morphometric results. Finally, the comparison of wing shape among temporally distant bug populations may be influenced by the cumulative effect of new bug generations (Dujardin et al. 2007, Schachter-Broide et al. 2009) and also further research on the relationship between wing shape and environmental variables is needed. A major strength is related to the detailed study of multiple georeferenced $T$. infestans populations collected before community-wide insecticide spraying and during the four-year follow-up, with clear a priori hypotheses that guided the research effort. Our preceding study in Area I enabled an extended comparison between neighbouring rural areas that showed contrasting re-infestation patterns.

Our results further support the use of wing geometric morphometry to investigate population structuring and house re-infestation at a spatial scale of $100 \mathrm{~km}^{2}$, a territory which has significant public health relevance. The re-infestation patterns recorded suggest that post-spray specimens most likely originated from external sources, unlike in Area I. The different patterns observed within the same municipality indicate the existence of apparently independent re-infestation processes. These results provide useful input to vector control programs in the Gran Chaco region and emphasise the need to expand the geographic coverage of vector surveillance and control operations to the affected region.

\section{ACKNOWLEDGEMENTS}

To Jorge Nasir, Cynthia Spillmann and the Chaco and National Chagas disease control programs, for continuing field support and advise, to Jean-Pierre Dujardin, Ana Laura Carbajal de la Fuente and Julieta Nattero, for helpful comments and discussions, and to Mundo Sano Foundation, for long-term accommodation at the study site.

\section{REFERENCES}

Abad-Franch F, Diotaiuti L, Gurgel-Gonçalves R, Gürtler RE 2013. Certifying the interruption of Chagas disease transmission by native vectors: cui bono? Mem Inst Oswaldo Cruz 108: 251-254.

Abrahan LB, Gorla DE, Catalá SS 2011. Dispersal of Triatoma infestans and other Triatominae species in the arid Chaco of Ar- 
gentina - Flying, walking or passive carriage? The importance of walking females. Mem Inst Oswaldo Cruz 106: 232-239.

Alvarado-Otegui JA, Ceballos LA, Orozco MM, Enriquez GF, Cardinal MV, Cura C, Schijman AG, Kitron U, Gürtler RE 2012. The sylvatic transmission cycle of Trypanosoma cruzi in a rural area in the humid Chaco of Argentina. Acta Trop 124: 79-86.

Bohonak AJ 2002. IBD (Isolation by Distance): a program for analyses of isolation by distance. $J$ Hered 93: 153-154.

Bookstein FL 1990. Introduction to methods for landmark data. In FJ Rohlf, FL Bookstein, Proceedings of the Michigan Morphometrics Workshop, The University of Michigan Museum of Zoology, Special Publication no 2, Ann Arbor, Washtenaw, p. 216-225.

Brenière SF, Salas R, Buitrago R, Brémond P, Sosa V, Bosseno M-F, Waleckx E, Depickère S, Barnabé C 2013. Wild populations of Triatoma infestans are highly connected to intra-peridomestic conspecific populations in the Bolivian Andes. PLoS ONE 8: e80786.

Ceballos LA, Piccinali RV, Marcet PL, Vázquez-Prokopec GM, Cardinal MV, Schachter-Broide J, Dujardin JP, Dotson EM, Kitron U, Gürtler RE 2011. Hidden sylvatic foci of the main vector of Chagas disease Triatoma infestans: threats to the vector elimination campaign? PLoS Negl Trop Dis 5: e1365.

Cecere MC, Vázquez-Prokopec GM, Ceballos LA, Boragno S, Zárate JE, Kitron U, Gürtler RE 2013. Improved chemical control of Chagas disease vectors in the Dry Chaco region. $J$ Med Entomol 50: 394-403.

Cecere MC, Vázquez-Prokopec GM, Gürtler RE, Kitron U 2006. Reinfestation sources for Chagas disease vector, Triatoma infestans, Argentina. Emerg Infect Dis 12: 1096-1102.

Dujardin JP, Beard CB, Ryckman R 2007. The relevance of wing geometry in entomological surveillance of Triatominae, vectors of Chagas disease. Infect Genet Evol 7: 161-167.

Dujardin JP, Cardozo L, Schofield C 1996. Genetic analysis of Triatoma infestans following insecticidal control interventions in central Bolivia. Acta Trop 61: 263-266.

Dujardin JP, Kaba D, Henry AB 2010. The exchangeability of shape. BMC Res Notes 3: 266.

Dumonteil E, Tripet F, Ramirez-Sierra MJ, Payet V, Lanzaro G, Menu F 2007. Assessment of Triatoma dimidiata dispersal in the Yucatan Peninsula of Mexico by morphometry and microsatellite markers. Am J Trop Med Hyg 76: 930-937.

Feliciangeli MD, Sanchez-Martin M, Marrero R, Davies C, Dujardin JP 2007. Morphometric evidence for a possible role of Rhodnius prolixus from palm trees in house re-infestation in the state of Barinas (Venezuela). Acta Trop 101: 169-177.

Fitzpatrick S, Feliciangeli MD, Sanchez-Martin MJ, Monteiro FA, Miles MA 2008. Molecular genetics reveal that silvatic Rhodnius prolixus do colonise rural houses. PLoS Negl Trop Dis 2: e210.

Gaspe MS, Gurevitz JM, Gürtler RE, Dujardin JP 2013. Origins of house reinfestation with Triatoma infestans after insecticide spraying in the Argentine Chaco using wing geometric morphometry. Infect Genet Evol 17: 93-100.

Gaspe MS, Provecho YM, Cardinal MV, Fernández MP, Gürtler RE 2015. Ecological and sociodemographic determinants of house infestation by Triatoma infestans in indigenous communities of the Argentine Chaco. PLoS Negl Trop Dis 9: e3614.

Gaspe MS, Schachter-Broide J, Gurevitz JM, Kitron U, Gürtler RE, Dujardin JP 2012. Microgeographic spatial structuring of Triatoma infestans (Hemiptera: Reduviidae) populations using wing geometric morphometry in the Argentine Chaco. J Med Entomol 49: 504-514.
Germano MD, Acevedo GR, Cueto GAM, Toloza AC, Vassena CV, Picollo MI 2010. New findings of insecticide resistance in Triatoma infestans (Heteroptera: Reduviidae) from the Gran Chaco. $J$ Med Entomol 47: 1077-1081.

Good P 2000. Permutation tests: a practical guide to resampling methods for testing hypotheses, Springer, New York, 228 pp.

Gorla DE, Porcasi X, Hrellac H, Catalá SS 2009. Spatial stratification of house infestation by Triatoma infestans in La Rioja, Argentina. Am J Trop Med Hyg 80: 405-409.

Gurevitz JM, Ceballos LA, Gaspe MS, Alvarado-Otegui JA, Enriquez GF, Kitron U, Gürtler RE 2011. Factors affecting infestation by Triatoma infestans in a rural area of the humid Chaco in Argentina: a multi-model inference approach. PLoS Negl Trop Dis 5: e1349.

Gurevitz JM, Gaspe MS, Enriquez GF, Provecho YM, Kitron U, Gürtler RE 2013. Intensified surveillance and insecticide-based control of the Chagas disease vector Triatoma infestans in the Argentinean Chaco. PLoS Negl Trop Dis 7: e2158.

Gurevitz JM, Gaspe MS, Enriquez GF, Vassena CV, Alvarado-Otegui JA, Provecho YM, Cueto GA, Picollo MI, Kitron U, Gürtler RE 2012. Unexpected failures to control Chagas disease vectors with pyrethroid spraying in northern Argentina. J Med Entomol 49: 1379-1386.

Gürtler RE 2009. Sustainability of vector control strategies in the Gran Chaco region: current challenges and possible approaches. Mem Inst Oswaldo Cruz 104 (Suppl. I): 52-59.

Gürtler RE, Canale DM, Spillmann C, Stariolo R, Salomon OD, Blanco S, Segura EL 2004. Effectiveness of residual spraying of peridomestic ecotopes with deltamethrin and permethrin on Triatoma infestans in rural western Argentina: a district-wide randomized trial. Bull World Health Organ 82: 196-205.

Gürtler RE, Kitron U, Cecere MC, Segura EL, Cohen JE 2007. Sustainable vector control and management of Chagas disease in the Gran Chaco, Argentina. Proc Natl Acad Sci USA 104: 16194-16199.

Hernández ML, Abrahan LB, Dujardin JP, Gorla DE, Catalá SS 2011. Phenotypic variability and population structure of peridomestic Triatoma infestans in rural areas of the arid Chaco (western Argentina): spatial influence of macro and microhabitats. Vector Borne Zoonotic Dis 11: 503-513.

Hernández ML, Dujardin JP, Gorla DE, Catalá SS 2013. Potential sources of Triatoma infestans reinfesting peridomiciles identified by morphological characterization in Los Llanos, La Rioja, Argentina. Mem Inst Oswaldo Cruz 108: 91-97.

Kaba D, Ravel S, Acapovi-Yao G, Solano P, Allou K, Bosson-Vanga H, Gardes L, N'Goran EK, Schofield CJ, Koné M, Dujardin JP 2012. Phenetic and genetic structure of tsetse fly populations (Glossina palpalis palpalis) in southern Ivory Coast. Parasit Vectors 5: 153.

Lardeux F, Depickère S, Duchon S, Chavez T 2010. Insecticide resistance of Triatoma infestans (Hemiptera, Reduviidae) vector of Chagas disease in Bolivia. Trop Med Int Health 15: 1037-1048.

Marcet PL, Mora MS, Cutrera AP, Jones L, Gürtler RE, Kitron U, Dotson EM 2008. Genetic structure of Triatoma infestans populations in rural communities of Santiago del Estero, northern Argentina. Infect Genet Evol 8: 835-846.

Noireau F, Cortez MGR, Monteiro FA, Jansen AM, Torrico F 2005. Can wild Triatoma infestans foci in Bolivia jeopardize Chagas disease control efforts? Trends Parasitol 21: 7-10.

Piccinali RV, Canale DM, Sandoval AE, Cardinal MV, Jensen O, Kitron U, Gürtler RE 2010. Triatoma infestans bugs in southern Patagonia, Argentina. Emerg Infect Dis 16: 887-889. 
Piccinali RV, Marcet PL, Noireau F, Kitron U, Gürtler RE, Dotson EM 2009. Molecular population genetics and phylogeography of the Chagas disease vector Triatoma infestans in South America. J Med Entomol 40: 796-809.

Porcasi X, Catalá SS, Hrellac H, Scavuzzo MC, Gorla DE 2006. Infestation of rural houses by Triatoma infestans (Hemiptera: Reduviidae) in southern area of Gran Chaco in Argentina. J Med Entomol 43: 1060-1067.

Rohlf FJ 1996. Morphometric spaces, shape components and the effects of linear transformations. Advances in Morphometrics 284: 117-129.

Samuels AM, Clark EH, Galdos-Cardenas G, Wiegand RE, Ferrufino L, Menacho S, Gil J, Spicer J, Budde J, Levy MZ, Bozo RW, Gilman RH, Bern C, Working Group on Chagas Disease in Bolivia and Peru 2013. Epidemiology of and impact of insecticide spraying on Chagas disease in communities in the Bolivian Chaco. PLoS Negl Trop Dis 7: e2358.

Schachter-Broide J, Dujardin JP, Kitron U, Gürtler RE 2004. Spatial structuring of Triatoma infestans (Hemiptera, Reduviidae) populations from northwestern Argentina using wing geometric morphometry. J Med Entomol 41: 643-649.
Schachter-Broide J, Gürtler RE, Kitron U, Dujardin JP 2009. Temporal variations of wing size and shape of Triatoma infestans (Hemiptera: Reduviidae) populations from northwestern Argentina using geometric morphometry. J Med Entomol 46: 994-1000.

Schofield CJ, Jannin J, Salvatella R 2006. The future of Chagas disease control. Trends Parasitol 22: 583-588.

Schofield CJ, Lehane MJ, McEwen PK, Catalá SS, Gorla DE 1992. Dispersive flight by Triatoma infestans under climatic conditions in Argentina. Med Vet Entomol 6: 51-56.

Schweigmann N, Vallvé S, Muscio O, Ghillini M, Alberti A, Wisnivesky-Colli C 1988. Dispersal flight by Triatoma infestans in an arid area of Argentina. Med Vet Entomol 2: 401-404.

Vázquez-Prokopec GM, Ceballos LA, Kitron U, Gürtler RE 2004. Active dispersal of natural populations of Triatoma infestans (Hemiptera: Reduviidae) in rural northwestern Argentina. $J$ Med Entomol 41: 614-621.

WHO - World Health Organization 2013. Neglected Tropical Diseases: innovative and intensified disease management. Available from: who.int/neglected_diseases/disease_management/en/. 